\title{
Entendendo o estado gerencial e sua relação com a educação: algumas ferramentas de análise*
}

\section{Understanding the managerial state: a few theoretical tools}

\author{
Iana Gomes de Lima* \\ Luís Armando Gandin***
}

\begin{abstract}
Resumo: O texto apresenta a construção de ferramentas teóricas para a análise do estado e das políticas públicas contemporâneas, com especial atenção às políticas educacionais. Com a contribuição de John Clarke e Janet Newman e agregando conceitos utilizados por Michael Apple e Stephen Ball, o texto oferece lentes teóricas para o exame da natureza gerencialista do Estado contemporâneo. Através de uma dispersão do poder, de borramento das fronteiras entre o público e o privado e de políticas avaliativas que controlam as ações das instituições públicas, o Estado gerencial combate o Estado de bem-estar social e cria as bases para políticas públicas que redesenham a relação entre sociedade civil e Estado. O texto conclui com algumas implicações para o campo de estudo das políticas educacionais, enfatizando que a lógica gerencialista não é transposta automaticamente, sem mediações, a todas as ações do estado.
\end{abstract}

Palavras-chave: Gerencialismo. Políticas educacionais. Estado.

\begin{abstract}
This article offers theoretical tools to the analysis of the state and contemporary public policies, with special attention to educational policies. Utilizing mainly the contribution of John Clarke and Janet Newman and adding the concepts used by Michael Apple and Stephen Ball, this article offer theoretical lenses to the examination of the managerial nature of the contemporary state. Through the dispersal of power, the blurring of the borders between public and private and assessment policies that control the action of public institutions, the managerial state fights the Welfare State and creates the conditions to public policies that reshape the relationship between civil society and the state. The article ends with some implications to the study of educational policies, emphasizing the fact that the managerial logic does not transfer, unmediated, to all state actions.
\end{abstract}

Keywords: Managerialism. Educational policies. State.

\footnotetext{
* Uma primeira versão, preliminar, deste artigo foi aprovada pelo GT Estado e Política Educacional da ANPED em 2011.

${ }^{* *}$ Professora de Ensino Fundamental da Escola Projeto. E-mail: <iana_glima@yahoo.com.br>

*** Professor da Faculdade de Educação da Universidade Federal do Rio Grande do Sul.

E-mail: <luis.gandin@ufrgs.br>
} 


\section{Introdução}

O objetivo desse artigo é discutir como a noção de gerencialismo pode contribuir para a análise dos atuais processos de reestruturação do Estado. Para o entendimento do gerencialismo, utilizamos centralmente as contribuições de John Clarke e Janet Newman (1997) no livro The Managerial State: power, politics and ideology in the remaking of Social Welfare, ainda sem tradução no Brasil. Neste livro, onde o conceito de Estado gerencial é forjado, os autores examinam as novas formas de administração e gerenciamento do Estado contemporâneo e, nesse processo, oferecem inúmeros conceitos-chave para aqueles, como nós, envolvidos em entender e analisar as políticas públicas. Agregando as contribuições da obra de Michael Apple (1999, 200, 2006) e de Stephen Ball (1998, 2001, 2004, 2010), buscamos construir um referencial teórico que dê conta da complexidade das atuais relações entre o estado, as políticas públicas e a educação.

No que se refere ao contexto brasileiro, o tema do gerencialismo é crucial, uma vez que as políticas sociais estão cada vez mais próximas da lógica gerencial de mercado. O gerencialismo traz à cena novas relações entre o Estado e o mercado, o que altera substancialmente a forma de conceber e implementar as políticas públicas. $\mathrm{O}$ artigo busca contribuir para a análise desses fenômenos.

\section{O surgimento do gerencialismo}

No livro The Managerial State: power, politics and ideology in the remaking of Social Welfare, publicado em 1997, os autores John Clarke e Janet Newman propõem uma discussão acerca da crise que o mundo ocidental experienciou, a partir dos anos de 1970, e que se constituiu em uma crise econômica de proporções globais que passou a apontar de forma clara e direta os limites econômicos e políticos do Estado de bem-estar social como pacto social (CLARKE; NEWMAN, 1997). É importante compreender tal crise, pois ela foi fundamental para o surgimento do gerencialismo como nova forma de administrar o estado.

Apple (1999) auxilia a entender essa crise. O autor afirma que, após a Segunda Guerra Mundial, houve uma espécie de acordo tácito entre o capital e o trabalho. Nesse acordo, o mundo do trabalho aceitou incluir a lógica do mercado e do lucro como as principais fontes de recursos; em contrapartida, os trabalhadores receberam garantias de padrões mínimos de vida em relação a seus direitos sociais. Falando dos Estados Unidos, Apple (1999) demonstra que essas conquistas passaram, a partir dos anos 1970, a ser questionadas em função "das crises econômicas e ideológicas que logo acossaram a sociedade americana” (APPLE, 1999, p. 45). Alguns fatores como a Guerra do Vietnã, a luta por igualdade racial e sexual e a tentativa de resistir à crise econômica provocaram choque e medo na população estadunidense (APPLE, 1999) e ajudaram a fazer 
com que a cultura até então dominante fosse questionada. Apple (1999) chama a atenção para o fato de que noções de família, comunidade e nação foram alteradas. Nessa lacuna de ideais sociais comuns, surgiu espaço para que grupos com características de direita propusessem enfrentar a crise com o retorno à moral e à ética alicerçadas em tradições familiares e, através de organizações financeiras estruturadas que tinham uma política agressiva, a um tradicionalismo religioso e cultural e a um compromisso populista (APPLE, 1999).

Com a crise de acumulação capitalista, não tardou a proposta de reestruturação do Estado. Para alguns grupos (como os neoconservadores, os neoliberais e a nova classe média), o Estado de bem-estar social estava privilegiando apenas as minorias, as quais tiveram conquistas importantes em termos de igualdade e direitos sociais, ao invés de favorecer os grupos que eram realmente merecedores de tais benefícios e que constituíam a "legítima" população da nação, neste caso os Estados Unidos (APPLE, 1999). No intuito de superar a incapacidade, em sua visão, do Estado de bem-estar social de solucionar a crise, uma nova aliança é estabelecida entre grupos aparentemente contraditórios, como neoliberais e neoconservadores. Um novo modelo de Estado emerge dessa aliança, que se estabelece em países como os Estados Unidos e o Reino Unido. A crítica ao Estado de bem-estar social ocorre principalmente a partir do que Apple (2000) chama de "Nova Direita": uma aliança entre neoliberais e neoconservadores, mas também entre grupos minoritários, como populistas autoritários e uma nova classe média profissional.

A Nova Direita passou a veicular um discurso que afirmava ser necessário reestruturar o Estado em termos econômicos, aplicando doutrinas de controle fiscal. Mas a novidade é um novo pensamento econômico que vê os gastos públicos como algo que impedia a viabilidade competitiva de indivíduos, empresas e da própria nação (CLARKE; NEWMAN, 1997). O contexto global de crise deu impulso aos novos discursos da Nova Direita que insistiam que a gestão baseada na burocracia era inapropriada e ineficiente e que não se adaptava às demandas complexas do mundo moderno.

Para que essa aliança hegemônica fosse constituída, foi preciso superar as contradições entre os próprios grupos que fazem parte da Nova Direita; foram necessários acordos e concessões no interior da própria aliança, o que mostra a complexidade e a fragilidade na formação da Nova Direita. Além dos acordos entre os próprios grupos, quando da reestruturação do Estado aqui tratada, foi preciso fazer com que o discurso veiculado pela Nova Direita em torno da necessidade de reformar o Estado se conectasse com os interesses, anseios, medos e desejos da população em geral, para que essa última pudesse perceber que o "guarda-chuva ideológico" - nas palavras de Apple (1999) - também tinha um espaço para "abrigar" os interesses mais gerais de todos. 
A Nova Direita é o grupo que veicula esse novo discurso, mostrando que a mudança é necessária para o crescimento do estado, transformando as organizações públicas e as políticas sociais (CLARKE; NEWMAN, 1997). É de suma importância a forma como a Nova Direita passa a criticar o Estado de bem-estar social, articulando suas ideias com as críticas existentes por parte de trabalhadores e cidadãos que se sentiam prejudicados nesse modelo de Estado:

A Nova Direita teve um papel fundamental na forma de falar da crise do Estado de bem-estar social. Ela se embasou em três temas principais para falar dessa crise: o custo que significava manter o Estado de bem-estar social, os efeitos do Estado de bem-estar social para as diferentes políticas e os problemas do mesmo. Isso gerou duas novas apostas por parte da Nova Direita: a do neoliberalismo, revivendo uma economia individualista, e o neoconservadorismo, revitalizando a tradição moral e a autoridade social. (CLARKE; NEWMAN, 1997, p. 14, tradução nossa).

Essas duas apostas trazidas pelos autores na citação acima foram fundamentais para a reestruturação do Estado. A Nova Direita trouxe à cena diretrizes do liberalismo, mas com alguns elementos novos. É a partir das críticas até aqui citadas que surge o gerencialismo, como uma resposta à crise que havia se estabelecido.

\section{Gerencialismo: principais ideias}

Com a crise global que ocorreu a partir dos anos de 1970 e com a articulação de diferentes grupos que formaram a Nova Direita, uma nova configuração do Estado passa a ter lugar, na qual há uma diminuição da prestação direta de serviços por órgãos públicos, que passa a ser realizada por agências localizadas em outros setores que não o Estado (CLARKE; NEWMAN, 1997). Uma das principais características é que o Estado passa a funcionar com os valores do mercado, o que provoca modificações no seu papel. A noção de mercado foi incluída de diferentes formas: privatização, contratação de serviços externos e taxação de serviços. Recentemente, foram também introduzidas as parcerias entre público e privado (CLARKE; NEWMAN, 1997). Castro (2008) ressalta que com a reestruturação do Estado o setor público passou a buscar uma nova forma de organização e gestão baseadas na iniciativa privada.

$\mathrm{Na}$ perspectiva do Estado gerencialista, o Estado passa a não ser mais o fornecedor de serviços, mas a ter principalmente um papel de gerenciador das políticas. Ocorrem, de forma simultânea, um encolhimento do estado e um alargamento de responsabilidades da sociedade civil (CLARKE; NEWMAN, 1997). O Estado passa, então, a ter um novo tipo de administração: o gerencialismo. Segundo Hypolito (2008), a construção do Estado gerencialista ocorreu sob uma 
aliança conservadora, e esse discurso influencia todos os campos da vida, inclusive o campo educacional. Tal administração vai ser o alicerce das novas políticas que se estabelecem para o Estado em reconstrução. Portanto, é fundamental que se compreenda o que significa o gerencialismo. Segundo Clarke e Newman (1997), ele pode ser definido como:

[...] a ideologia que dá sentido à prática da organização do poder como dispersivo. O gerencialismo procura ativamente distribuir responsabilidades, aumentando a sua abrangência através de corporações e indivíduos. Estabelece-se como uma promessa de transparência dentro de um campo complexo de tomada de decisão. Ele está comprometido com a produção de eficácia na realização de seus objetivos, de forma super-ordenada. Gerencialismo representa o cimento que pode unir essa forma de dispersão de organização do Estado e, na sua orientação para o cliente, afirma ser capaz de representar um anúncio de serviço público individualizado. $\mathrm{O}$ gerencialismo promete fornecer a disciplina necessária para que as organizações sejam eficientes, particularmente em relação às políticas de bem-estar, sendo que cada indivíduo tem a capacidade de escolher de forma livre. Essas promessas articulam uma nova base para a apreciação de um novo gerencialismo: a liberdade de fazer a coisa certa. (CLARKE; NEWMAN, 1997, p. 30, tradução nossa).

A citação acima ajuda a compreender as diferentes características do gerencialismo que as torna peça fundamental na reestruturação do Estado. Primeiramente, o gerencialismo se configura em uma dispersão de poder, atribuindo a diversas instâncias - desde indivíduos, até corporações - a responsabilidade que antes era do Estado. Em segundo lugar, compromete-se com a transparência de sua governabilidade - crítica feita ao modelo burocrático. Em terceiro lugar, estabelece metas e objetivos claros a serem alcançados, o que dá a ideia de eficácia, pois a sociedade e o próprio governo podem verificar se tais objetivos foram atingidos. E em quarto lugar traz a ideia do indivíduo como um ente que deve ser central e cujos interesses devem ser atendidos (CLARKE; NEWMAN, 1997). Além disso, o gerencialismo ou gestão gerencial também tem como características a redução e o controle dos gastos públicos e o modelo de avaliação por desempenho - que será fundamental no âmbito educacional (CASTRO, 2008).

O discurso da eficiência é fundamental e está diretamente relacionado às propostas do gerencialismo. Uma das grandes críticas da Nova Direita ao Estado de bem-estar social era a ineficiência de sua administração e do mau gerenciamento das instituições e das políticas estatais. Na reconstrução do Estado, muito foi dito em relação à falta de capacidade do Estado de bem-estar social em fazer com que as nações, principalmente no caso do Reino Unido e dos Estados Unidos, fossem competitivas no cenário mundial. Essa crítica reforçava a ideia de que esse "velho" Estado era ineficiente. Para garantir tal eficiência, principalmente no que 
diz respeito ao setor público, se pressupõe, a partir da reestruturação, uma maior disciplina e controle para que se tenha, assim, uma relação de custo-eficácia, diminuindo os gastos públicos (CLARKE; NEWMAN, 1997). Os grupos que começaram a se constituir como hegemônicos, após a crise do Estado de bemestar social, passaram a veicular um discurso no qual havia uma dura crítica às instituições públicas, apontando suas falhas e sua ineficiência tanto na gestão quanto no oferecimento de seu produto, que é indicado como de má qualidade. É importante destacar que esse discurso tem elementos que se conectam com a realidade vivida pelos indivíduos, ou seja, ele não é um discurso puramente "falso", pois, durante o Estado de bem-estar social, parte da população, incluindo os grupos minoritários, criticava o Estado (e suas instituições públicas) por suas políticas sociais não serem suficientes para diminuir as desigualdades sociais e pelos direitos adquiridos serem limitados (APPLE, 1999; HARVEY, 1989). No entanto, os grupos hegemônicos trataram de reforçar a ideia de que tudo o que é ruim provém do Estado e, logo, do público; enquanto aquilo que é eficiente e de qualidade faz parte do âmbito privado, das empresas e do mercado. Assim, começa a se difundir a noção de que é preciso inserir a lógica do mercado nas instituições públicas para que se obtenha um serviço de qualidade e de sucesso. $\mathrm{O}$ que se quer é apontar a necessidade de modificar o tipo de gestão das instituições públicas e mostrar que a lógica do mercado é a mais eficiente para as diferentes políticas, inclusive as sociais e as educacionais. Como diz Tomaz Tadeu da Silva (1995), as questões políticas e sociais são transformadas em questões técnicas: não se tratam tais questões como sendo objetos e resultados de lutas em torno da "distribuição desigual de recursos materiais e simbólicos e de poder" (SILVA, 1995, p. 18), mas como fruto de uma eficiência ou ineficiência por parte do gerenciamento e da administração de tais recursos.

O novo gerencialismo que começa a ser implantado nas instituições públicas é alicerçado em teorias e técnicas de gerência empresarial, do "culto da excelência" (BALL, 1998) e da lógica do mercado, o que acarreta profundas modificações no Estado. Segundo Ball (2001), o documento da Organização para a Cooperação e o Desenvolvimento Econômico (OCDE ou OECD em inglês), intitulado Governance in Transition: Public Management Reforms in OECD Countries, traz elementos importantes para que se compreenda de que maneira essa forma de administração passa a gerir os órgãos públicos. O documento aborda pontos essenciais em relação a essa nova gestão: atenção focada nos resultados, verificando se há eficiência, qualidade e eficácia dos serviços; gestão descentralizada, o que significa dizer que a decisão sobre a prestação de serviços está mais próxima do local no qual será aplicada e pode, assim, contar com uma avaliação dos clientes para o qual o serviço é prestado; e criação de ambientes competitivos dentro das instituições públicas e de objetivos claros de produtividade. Perante 
essas transformações, a natureza do Estado é modificada: esse passa de provedor a gestor. O Estado não sofre simplesmente uma desregulação: ele é rerregulado (BALL, 2001), ou seja, o Estado continua tendo controle sobre as políticas, mas o tipo de controle é modificado. O Estado, nessa perspectiva, passa a administrar os recursos e as políticas. O próprio poder do Estado sofre modificações.

Com a nova política do Estado, as políticas sociais passaram a ser compreendidas por outra perspectiva: a linguagem começa a ser a da eficiência, a concorrência dos mercados, o consumismo e o atendimento ao cliente (CLARKE; NEWMAN, 1997). O que se pode observar é que, nesta reconfiguração do Estado, tais políticas estão muito associadas ao econômico e à ideia de mercado. Isso significa dizer que as políticas sociais passam a atender aos interesses do capital em termos de eficiência e qualidade na prestação de serviços e são vinculadas ao pressuposto de que é necessário que o Estado gaste menos com as políticas sociais. A defesa - como já citada anteriormente - é que o Estado seja diminuído em termos de prestação de serviços sociais. Portanto, as políticas sociais passam a ser compreendidas como produtos que são administrados e controlados através de princípios do mercado. Outra questão que relaciona as políticas sociais à economia é o fato de que os organismos internacionais (Banco Mundial, Fundo Monetário Internacional etc.) estabelecem metas para os países quanto às políticas sociais e os gastos com essas políticas. O cumprimento de tais metas, para os organismos internacionais, demonstra a eficiência dos países e a sua capacidade em serem competitivos no cenário mundial (algo muito importante nessa reestruturação do Estado, dada a crise que estava estabelecida). No entanto, cabe ressaltar que os organismos internacionais não determinam as políticas de cada país. É claro que eles representam uma forte influência, mas segundo Ball (2004, p. 1115), há uma "glocalização, isto é, a acomodação de tendências globais em histórias locais, [...] [produzindo] políticas híbridas e diversidade política". A relação entre os organismos internacionais e as instâncias locais reforça a complexidade da reestruturação do Estado.

As metas estabelecidas pelos organismos internacionais estimulam a competição (aspecto atrelado ao campo econômico), que se relaciona com o Estado gerencial em termos da diminuição de gastos com as políticas sociais. Como a política social é uma das tarefas do Estado - mesmo que passe a ser responsabilidade de outras entidades, o Estado ainda tem o compromisso de avaliá-la - ela também precisa ser economicamente viável, já que o capital e o mercado são os aspectos mais importantes nessa nova forma de Estado. As políticas sociais, que antes eram oferecidas para o cidadão no Estado de bem-estar social, passam a ser oferecida ao consumidor e/ou cliente no Estado gerencialista. O cidadão passa a ser entendido como um cliente que pode comprar determinado produto, podendo esse produto ser, inclusive, uma política social. 
Sobre essa nova reestruturação do estado, é muito comum ouvir que o poder foi descentralizado, ou, na expressão mais comum, que o Estado passou a ser mínimo. No entanto, estudos (CLARKE; NEWMAN, 1997; BALL, 1998) mostram que há uma contradição nesta questão: ao mesmo tempo em que o poder se descentralizou, ele também foi centralizado sobre outros aspectos. É possível afirmar que a execução de muitas das políticas públicas foi delegada a outras instituições e a própria sociedade civil. Tal aspecto mostra a descentralização do poder do estado. Todavia, a centralização pode ser percebida através do controle que há sobre a execução dos serviços por parte do Estado. Esse controle ocorre centralmente através de avaliações sistemáticas dos resultados das políticas, que passam a ser medidos através de indicadores quantitativos da performance (CLARKE; NEWMAN, 1997).

Segundo Clarke e Newman (1997), a descentralização do poder do Estado ocorre através da privatização. Os autores ainda afirmam que existem três formas diferentes de privatização. A primeira delas é a venda de bens públicos para empresas privadas. A segunda maneira é o borramento das fronteiras entre o público e o privado, ou seja, quando são implementadas em órgãos públicos as noções de gestão de empresas privadas, reestruturando-os e reorganizando-os, principalmente a partir da ideia de competição interna. É diferente da primeira noção de privatização, pois não significa a venda direta para uma empresa privada, mas a implementação das ideias do privado dentro do público. Essa segunda forma é o que Clarke e Newman (1997) chamam "parcerias público-privadas". Os autores ainda lembram que essa segunda forma significa uma diminuição da diferença entre o público e o privado, mas não uma remoção total das características que os distingue. A terceira forma consiste em mudar a responsabilidade do Estado para o setor informal (CLARKE; NEWMAN, 1997). Nesse tipo de privatização, é esperado que a comunidade (indivíduos e organizações) assuma o papel de provedor dos serviços sociais. Tal forma atende diretamente aos interesses neoconservadores, que estão ligados à tradição cultural e aos princípios da família. Quando a prestação de serviços sociais passa a ser de responsabilidade da comunidade, esses valores ditos tradicionais pelos neoconservadores - atenção com a saúde, cuidado, boa educação - são chamados à cena e é como se a prestação de tais serviços retornasse àqueles que são entendidos como os "provedores naturais".

Essa contradição em torno da descentralização e da centralização também pode ser percebida na forma de controle exercida pelo Estado gerencialista. Um dos pressupostos do gerencialismo é o controle a distância (BALL, 1998). A descentralização é vista pela transferência da responsabilidade para outras instituições em prover políticas sociais, enquanto que a centralização é percebida na figura do Estado, que gerencia os resultados de tais políticas através 
de mecanismos de controle, os quais podem ter uma avaliação padronizada, estabelecimento de metas e objetivos etc. Ball (1998) lembra que o gerencialismo se distancia dos métodos tayloristas de controle, pois nesse tipo de administração há uma perspectiva positiva do trabalhador e não uma posição de pouca confiança. $\mathrm{O}$ gerencialismo tem como mecanismo delegar funções e valoriza quando os trabalhadores que são responsabilizados por determinada tarefa têm iniciativa para resolver problemas que surgem ao longo de sua execução. Aqui é possível perceber a intersecção entre a descentralização empregada pelo gerencialismo e da noção de individualidade: o sucesso está atrelado a cada indivíduo na medida em que ele consegue atingir objetivos e metas. Há, portanto, uma valorização individual que, muitas vezes, pode ser recompensada com prêmios e destaques dentro da instituição na qual o trabalhador atua. Ball (1998), ao mesmo tempo em que mostra a descentralização existente no gerencialismo, também destaca que "novas formas de vigilância e autocontrole são instituídas" (BALL, 1998, p. 128). O que fica claro, mais uma vez, é a noção do estado como gerenciador, que passa a administrar as diversas instituições para as quais foram delegadas o que antes eram suas funções.

O que foi descrito acima compõe as principais ideias que embasam o estado gerencialista. No próximo subitem, trataremos de discutir, ainda que brevemente, o cuidado que nos parece ser necessário no uso desse conceito como ferramenta analítica para exame do Estado brasileiro, tendo em vista as particularidades de cada locus.

\section{Gerencialismo como ferramenta analítica do caso brasileiro}

Os pressupostos do gerencialismo também servem como alicerce de muitas das políticas sociais que passam a ser implementadas no Brasil a partir dos anos de 1990. No entanto, a reestruturação do Estado brasileiro não foi totalmente igual ao caso dos Estados Unidos e Inglaterra, o que reforça o conceito de glocalização (BALL, 2004).

Muitos dos aspectos acima citados podem ser percebidos na prática do Estado brasileiro quanto às políticas públicas, principalmente nas políticas educacionais: inserção da lógica do mercado, estabelecimento de competição entre agências não-estatais, repasse da responsabilidade para setores não-estatais, avaliação dos resultados, entre outras. Portanto, é possível analisar o Estado brasileiro pela lente do gerencialismo; é preciso, contudo, estar atento para as particularidades brasileiras, que não permitem com que seja afirmado que o Estado brasileiro é puramente gerencialista.

No contexto brasileiro, por exemplo, as parcerias público-privadas, citadas por Clarke e Newman (1997), como uma das formas de privatização no 
estado gerencialista, não ocorrem necessariamente através de uma parceria entre uma instituição pública e uma privada. Muitas vezes, a inserção da lógica do privado dentro do público acontece através da noção de quase-mercado, pois, no caso brasileiro, não existe necessariamente o parceiro privado, mas apenas a inserção da lógica do mercado na instituição pública. Whitty (1997) afirma que o quase-mercado é o processo no qual valores de mercado são adotados nas instituições públicas. Para esse autor, a noção de quase-mercado difere-se de privatização, pois essa última inclui transferir uma instituição do poder público para o privado. No quase-mercado não ocorre essa transferência, mas uma mercadificação das instituições, o que inclui, como já dito, a inserção da lógica do privado no público. Whitty (1997) ressalta que o quase-mercado envolve a combinação entre responsabilidade social (no caso brasileiro, isso pode ser entendido como a delegação de funções antes estatais para instituições não-estatais) e regulação governamental. Essa regulação por parte do Estado também é um ponto importante no uso do conceito de quase-mercado, diferenciando-o de privatização, já que nesse último o Estado não teria mais nenhum tipo de responsabilidade ou interferência. Esse conceito se aproxima da segunda forma de privatização de Clarke e Newman (1997), já citada acima, em que há o borramento das fronteiras entre o público e o privado. No Brasil, a noção de quase-mercado foi incluída nas instituições escolares, principalmente, através das avaliações. Segundo Souza e Oliveira (2003, p. 879) as avaliações

[...] têm servido para viabilizar uma lógica de gerenciamento da educação, reconfigurando, por um lado, o papel do Estado e, por outro, a própria noção de educação pública, ao difundir uma ideia de qualidade que supõe diferenciações no interior dos sistemas públicos de ensino, como condição mesma de produção de qualidade.

O que os autores destacam é que as avaliações serviram para inserir a lógica do mercado dentro das instituições escolares, através de marcadores empresariais para a noção de qualidade. As avaliações também estão circunscritas em novo papel para o Estado brasileiro que passou a ser um gerenciador das políticas públicas providas por outras instituições não-estatais.

Outro aspecto que apresenta uma particularidade do Brasil é a intervenção estatal ainda existente nas políticas sociais. O modelo de Estado gerencialista envolve a noção de que o Estado deixa de ser o provedor das políticas sociais e passa a geri-las (CLARKE; NEWMAN, 1997). Nessa perspectiva, o Estado torna-se um avaliador das políticas públicas providas por outras instituições e controla a eficiência dos serviços que são prestados por tais instituições. A avaliação do Estado sobre as políticas públicas ocorre através de marcadores de mercado, pois é o mercado (âmbito privado que se contrapõe ao público) que passa a ser o modelo de eficiência e qualidade. Na perspectiva do Estado gerencialista, há 
um enxugamento da máquina estatal em termos de recursos humanos, a qual já que não precisará mais prover as políticas e somente avaliá-las. No entanto, em uma pesquisa realizada no Rio Grande do Sul, em que se analisou a adoção por escolas estatais de sistemas apostilados de ensino ${ }^{1}$, foi possível perceber que o Estado não é apenas um avaliador/regulador dos serviços sociais, como também ainda um provedor. Nesse caso, órgãos do Estado eram responsáveis por realizar a formação das docentes que trabalhariam com o sistema de apostilamento, ou seja, as pessoas que trabalhavam na Secretaria de Educação do Rio Grande do Sul iam até as escolas verificar se havia algum problema na implementação e, caso necessário, prestavam o auxílio para tal.

Nessa perspectiva, entra em jogo a noção de Estado mínimo, que tanto é mencionando quando da adoção dos pressupostos gerencialistas e neoliberais pelo Estado. A perspectiva de Estado mínimo pode ser compreendida em duas ênfases: no repasse de responsabilidade para instituições não-estatais em pensar uma política pública educacional para a alfabetização das escolas estaduais e na diminuição dos recursos humanos da máquina do Estado. Contudo, nesse caso, há uma contradição em relação ao Estado mínimo à medida que ele precisa gerenciar e controlar as políticas públicas. Apple (1999) corrobora essa noção ao dizer que o neoliberalismo implica um Estado muitas vezes forte devido ao controle curricular que precisa exercer.

Essa questão da força que ainda existe no Estado também pode ser vista através dos inúmeros programas que o Governo Federal tem no âmbito social. Isso mostra o quanto o Estado brasileiro ainda ocupa uma posição central no provimento das políticas sociais.

\section{Estado Gerencialista e algumas Implicações para as Políticas Educacionais}

Como já visto acima, a reforma do Estado transformou de forma intensa as políticas sociais. Isso não significa dizer que apenas a prestação de tais serviços passou a ser exercida por outras instituições que não pertencem ao Estado, mas também que as próprias políticas sociais em si foram modificadas a partir de novos pressupostos de gestão, de qualidade e de eficiência. As políticas educacionais também sofreram alterações, o que acarretou profundas modificações nas escolas. Castro (2008, p. 392) afirma que "a concepção de modernização da gestão de caráter gerencial vem sendo introduzida no âmbito das reformas educacionais como uma estratégia fundamental para garantir o sucesso escolar".

\footnotetext{
${ }^{1}$ Segundo Adrião e demais autoras, os sistemas apostilados de ensino ou sistemas de ensino "[...] oferecem serviços e produtos, tais como materiais didáticos para alunos e professores, incluindo apostilas e CD-ROMs, formação docente em serviço e monitoramento do uso dos materiais adquiridos" (ADRIÃO et al., 2009, p. 802).
} 
Ball (1998) destaca que parte da reforma do Estado no que diz respeito às políticas educacionais também dependeu do novo discurso hegemônico que passou a ser veiculado. Nesse discurso, havia críticas e ridicularizações em relação às políticas anteriores, que passaram a ser "descritas como impensáveis". Além disso, esse discurso passou a culpar as políticas anteriores pela ineficiência e pela falta de qualidade da educação. Essa culpa, segundo Ball (1998), fez com que as novas políticas se tornassem ainda mais atraentes por representarem a inovação. Ball (2010) também destaca que a nova política educacional abriu espaço para um novo jeito de falar sobre educação, embasada em discursos da aliança hegemônica que se formou e que "encarnaram e disseminaram narrativas de soluções empresariais e empreendedoras para problemas sociais e educacionais" (BALL, 2010, p. 159, tradução nossa).

A nova forma de gestão do Estado, ou seja, o gerencialismo, também trouxe mudanças no âmbito educacional. Assim como a Nova Direita atribuiu a má gestão do Estado à crise capitalista, na educação a culpabilização daquilo que foi apontado como falta de qualidade e pouca eficiência recaiu sobre a má administração das escolas. Silva (1995) auxilia a compreender de que forma passaram a ser entendidas as dificuldades pelas quais passava a escola pública:

[...] a situação desesperadora enfrentada cotidianamente em nossas escolas por professoras/es e estudantes é vista como resultado de uma má gestão e desperdício de recursos por parte dos poderes públicos, como falta de produtividade e esforço por parte de professores/as e administradores/as educacionais, como conseqüência de métodos "atrasados" e ineficientes de ensino e de currículos inadequados e anacrônicos. (SILVA, 1995, p. 19).

A citação acima ajuda a entender que as dificuldades da escola pública passaram a ser atribuídas à sua má gestão. Assim, o discurso político educacional que passou a ser veiculado pelo Estado era de que se faziam necessárias mudanças na forma de administrar a instituição escolar. Esse discurso passou a ter novos marcadores que, assim como no Estado, estavam profundamente relacionados à lógica do mercado e traziam a linguagem do mundo do trabalho para dentro das escolas (SILVA, 1995). Começou a se falar em eficiência, qualidade e produtividade nas instituições escolares. Essas ideias foram traduzidas para o âmbito escolar de diversas formas, entre as quais, pode-se destacar a que foi denominada de Gestão da Qualidade Total. Para Silva (1995, p. 20), essa gestão se traduz em uma nova forma de "tentar organizar as escolas e as salas de aula com esquemas de organização do mundo do trabalho".

Ball (1998) identifica um conjunto de ideias que atuaram para reformar o Estado e que influenciaram no âmbito da educação. Para o autor, são cinco elementos principais para essa reforma (neoliberalismo, nova economia 
institucional, performatividade, teoria da escolha pública e novo gerencialismo), os quais se relacionam entre si, não atuando de forma isolada. Dentre esses elementos, destaca-se a performatividade, pois ela atua de forma bastante presente nas políticas educacionais, através da forma como o controle é exercido nas escolas. Para Ball (1998, p. 127), a performatividade é

[...] um mecanismo de controle, uma forma de controle indireto ou de controle a distância que substitui a intervenção e a prescrição pelo estabelecimento de objetivos, pela prestação de contas e pela comparação. Além disso, como parte da transformação da educação e da escolarização e da expansão do poder do capital, a performatividade fornece sistemas de signos que "representam" a educação de uma forma auto-referencial e reificada para o consumo. E, na verdade, muitas das tecnologias específicas de performatividade em educação (Gerência de Qualidade Total, Gerência de Recursos Humanos, etc.) são tomadas de empréstimo de contextos comerciais.

A citação acima mostra a relação que há entre diversos elementos que serviram de alicerce para a reestruturação do Estado. Quando Ball trata da performatividade, indicando-a como uma forma de controle a distância, é possível relacioná-la com a ideia de Estado gerencialista apresentada anteriormente. O Estado gerencialista tem como um de seus pressupostos maior autonomia por parte do trabalhador e o controle dos resultados ao invés do processo. Esses aspectos do gerencialismo formam a base para a performatividade, tornando o controle algo mais abstrato e distante.

Outra mudança trazida pelas ideias gerencialistas para o âmbito educacional é a ênfase dada à avaliação, o que acarreta uma nova forma de controle por parte do Estado: ao invés de controlar/avaliar o processo, o gerencialismo foca o resultado. Na educação, tal pressuposto se traduziu, principalmente, em avaliações escolares.

\section{Reflexões finais}

Nesse artigo buscamos construir um referencial teórico para a análise do estado contemporâneo e das políticas públicas, em especial aquelas destinadas à educação. Nosso esforço foi, propositalmente, de definição de uma lente macrossociológica, que ajuda a levar em conta os grandes deslocamentos do estado capitalista contemporâneo através do conceito de gerencialismo. Obviamente entendemos que há a necessidade de, ao aplicar essa lente à realidade brasileira, compreender as mediações nacionais e também as negociações dos espaços institucionais microssociológicos.

Ressaltamos a importância da continuidade da análise desse referencial teórico para compreender o contexto do Estado brasileiro e suas políticas 
educacionais. Esse é um trabalho intelectual que fica para um próximo trabalho. No entanto, é possível esboçar alguns ensaios. Como dissemos acima, a avaliação passou a ser um elemento central do estado gerencial; essa é a forma de controle que o Estado gerencialista exerce, ou seja, ao invés de controlar/avaliar o processo, o gerencialismo foca o resultado. $\mathrm{Na}$ educação, tal pressuposto se traduziu em avaliações escolares. No Brasil, particularmente, a avaliação passou a ser uma exigência do Banco Mundial para a liberação de empréstimos (PERONI, 2003). O Estado, além de cumprir essa exigência, também julgou importante a elaboração de uma avaliação institucional em termos nacionais a partir dos pressupostos de que o Estado gerencialista deveria ter controle sobre os resultados das políticas sociais, e das educacionais em particular. Segundo Peroni (2003), alguns fatores contribuíram para que o Estado mostrasse interesse em ter uma avaliação institucional: a existência em diferentes estados do Brasil de avaliações de projetos, mas não de políticas; a falta de uma avaliação geral, já que os projetos partiam de pressupostos diferentes em níveis estaduais e municipais; e o processo de redemocratização, já que havia pouca transparência na avaliação.

Assim como outras políticas sociais, as políticas educacionais também passaram a ser oferecidas por outras instituições não pertencentes ao Estado. É o caso, por exemplo, da adoção de sistemas apostilados de ensino ou sistemas de ensino (ADRIÃO et al., 2009) em vários estados do país (São Paulo, Minas Gerais, Rio Grande do Sul etc.). Segundo Adrião e demais autoras, os sistemas de ensino " $[. .$.$] oferecem serviços e produtos, tais como materiais didáticos para$ alunos e professores, incluindo apostilas e CD-ROMs, formação docente em serviço e monitoramento do uso dos materiais adquiridos" (ADRIÃO et al., 2009, p. 802). Esses sistemas acabam repassando a responsabilidade da educação e, principalmente, da elaboração do currículo para instituições externas ao Estado. Tal política se insere na lógica gerencial, na qual há a diminuição da responsabilidade do Estado por políticas públicas.

Ao concluir, enfatizamos que tratamos aqui de buscar uma visão macrossocial, relacionando a reestruturação do Estado e as modificações na maneira de pensar políticas. No entanto, as políticas públicas não são fruto apenas das ideias que alicerçam o Estado e dos grupos hegemônicos que o compõem, o que significa dizer que elas não são implementadas de forma direta e sem nenhuma resistência nas escolas: há também a ação dos sujeitos que estão nas instituições escolares e que vão, em certa medida, reformular muitas dessas políticas. A análise de políticas públicas precisa considerar essas mediações se quer dar conta da complexidade da sua concepção, circulação e implementação. 


\section{Referências}

ADRIÃO, T. et al. Uma modalidade peculiar de privatização da educação pública: a aquisição de sistemas de ensino por municípios paulistas. Educação \& Sociedade, Campinas, v. 30, n. 108, p. 799-818, out. 2009. DOI: 10.1590/S0101-73302009000300009

APPLE, M. W. Conhecimento oficial: a educação democrática numa era conservadora. Tradução de Maria Isabel Edelweiss Bujes. 2 ed. Petrópolis: Vozes, 1999.

Política cultural e educação. Tradução de José do Amaral Ferreira. São Paulo: Cortez, 2000.

Ideologia e currículo. Tradução de Vinicius Figueira. 3 ed. Porto Alegre: Artmed, 2006.

BALL, S. J. Cidadania Global, Consumo e Política Educacional. In: SILVA, L. H. da (Org.). A Escola Cidadã no contexto da globalização. Petrópolis: Vozes, 1998. p. 121-137.

. Diretrizes Políticas Globais e Relações Políticas Locais em Educação. Educação \& Realidade, Porto Alegre, v. 1, n. 2, p. 99-116, jul./dez. 2001.

Performatividade, privatização e o pós-estado do bem-estar. Educação \& Sociedade, Campinas, v. 25, n. 89, p. 1105-1126, set./dez. 2004. DOI: 10.1590/S010173302004000400002

. New states, new governance and new education policy. In: APPLE, M. W.; BALL, S. J.; GANDIN, L. A. The Rutledge International Handbook of the Sociology of Education. Milton Park: Routledge, 2010. p. 155-166.

CASTRO, A. M. D. A. Administração gerencial: a nova configuração da gestão da educação na América Latina. Revista Brasileira de Política e Administração da Educação, Porto Alegre, v. 24, n. 3, p. 389-406, set./dez. 2008.

CLARKE, J.; NEWMAN, J. The managerial state: power, politics and ideology in the remaking of Social Welfare. London: Sage Publications, 1997.

HARVEY, D. Condição pós-moderna. Tradução de Adail Ubirajara Sobral e Maria Stela Gonçalves. 7. ed. São Paulo: Edições Loyola, 1989.

HYPOLITO, A. L. M. Estado gerencial, reestruturação educativa e gestão educacional. Revista Brasileira de Política e Administração da Educação, Porto Alegre, v. 24, n. 1, p. 63-78, jan./abr. 2008.

PERONI, V. Política educacional e papel do estado: no Brasil dos anos 1990. São Paulo: Xamã, 2003.

SILVA, T. T. da. A "nova" direita e as transformações na pedagogia da política e na política da pedagogia. In: GENTILI, P. A. A.; SILVA, T. T. da (Orgs.). Neoliberalismo, qualidade total e educação: visões críticas. 2. ed. Petrópolis: Vozes, 1995. p. 9-30.

SOUZA, S. Z. L. de; OLIVEIRA, R. P. de. Políticas de avaliação da educação e quase mercado no Brasil. Educação \& Sociedade, Campinas, v. 24, n. 84, p. 873-895, set. 2003. DOI: 10.1590/S0101-73302003000300007 
WHITTY, G. Creating quase-markets in education: a review of recent research on parental choice and school autonomy in three countries. Review of Research in Education, v. 22, n. 1, p. 3-47, 1997. DOI: 10.3102/0091732X022001003

Recebido em 08/01/2012

Versão final recebida em 17/03/2012

Aceito em 20/03/2012 